\title{
Mapping the Business Value of the Internet of Things
}

\author{
Pierangelo Rosati and Theo Lynn
}

\begin{abstract}
The impacts of enterprise investments in technological infrastructure for the Internet of Things (IoT) go well beyond the technical domain and require significant changes in an enterprise's operations, strategy and approach to market. This chapter presents a framework for mapping the business value of IoT investments which aims to support managers in their decision-making process by providing an overview of how specific resources need to be linked together in order to generate business value. The presented framework is also used as a point of reference for identifying current research gaps which may represent avenues for future research.
\end{abstract}

Keywords Internet of Things $\bullet$ Business value $\bullet$ Information technology $\bullet$ Strategy $\bullet$ Value mapping

P. Rosati $(\bowtie) \bullet$ T. Lynn

Irish Institute of Digital Business, DCU Business School, Dublin, Ireland e-mail: pierangelo.rosati@dcu.ie; theo.lynn@dcu.ie

(C) The Author(s) 2020

T. Lynn et al. (eds.), The Cloud-to-Thing Continumm, Palgrave

Studies in Digital Business \& Enabling Technologies, https://doi.org/10.1007/978-3-030-41110-7_8 


\subsection{INTRODUCTION}

Digital transformation is causing a strategic shift in organisations. Driven by key enabling technologies - big data analytics, cloud computing, mobile and social technologies-IT spending has been on the increase worldwide and forecasts to reach $\$ 6$ trillion by 2022 (IDC 2018). While each of these technologies generates business and economic value on their own, they create much greater benefits when combined in to innovative solutions such as the Internet of Things (IoT) (Rosati et al. 2017).

Haller et al. (2009, p. 15) define IoT as "a world where physical objects are seamlessly integrated into the information network, and where the physical objects can become active participants in business processes. Services are available to interact with these 'smart objects' over the Internet, query their state and any information associated with them, taking into account security and privacy issues." Even though the idea of connecting physical objects to the digital worlds is not completely new, the decreasing cost of sensors and computing resources, improvements in computing power and network infrastructures, and the flexibility and agility provided by cloud computing have made it possible for organisations to operationalise large IoT solutions (Agrawal et al. 2011; Ji et al. 2012; Sagiroglu and Sinanc 2013).

While most of the academic discussion has focused on the technical aspects of IoT, it should be noted that it also generates significant business opportunities (Côrte-Real et al. 2019; Wolf et al. 2019). Recent studies have investigated how IoT impacts organisations' business model (e.g., Fleisch et al. 2015; Dijkman et al. 2015; Metallo et al. 2018; Wolf et al. 2019) and how specific aspects of IoT may affect business value creation and extraction (e.g., Karkouch et al. 2016; Côrte-Real et al. 2019). However, clear methodologies for mapping, and indeed measuring, the business value of IoT are still missing.

This chapter aims to fill this gap by introducing a framework for mapping the enterprise business value of IoT and exploring the main cost and value drivers associated with IoT investments. The remainder of this chapter is organised as follows. Next, we introduce the typical IoT architecture and provide some exemplar use cases. Then we introduce the proposed mapping framework and discuss the main cost and value components. Finally, we conclude the chapter with a discussion and avenues for future research. 


\subsection{The Internet of Things}

As discussed in Chap. 1, the term "IoT" is often used as an umbrella term for describing various aspects related to the extension of the Internet in to the physical world through "smart" devices (Miorandi et al. 2012). From a business perspective, IoT can be seen as an innovative hybrid construct which consists of two elements, the "thing" and the digital service, that are strictly interconnected in order to generate value (Fleisch et al. 2015). These two elements are brought together through a complex, modular, multi-layered architecture similar to the one represented in Fig. 8.1.

In the device layer, sensors and actuators transform real-word events in to digital signals (Ji et al. 2012). The network layer provides the network structure that allows a high number of connected devices to send information securely and with low latency (ITU 2012). The support layer provides the main functions related to data processing while the application layer provides the user interface of specific IoT application (ITU 2012).

According to recent estimates, worldwide hardware and software IoT spending is projected to grow, from $\$ 726$ billion in 2019 to $\$ 1$ trillion in 2022 (IDC 2019), and IoT solutions are expected to generate $\$ 4.6$ trillion in value for the public sector and another $\$ 14.4$ trillion for the private

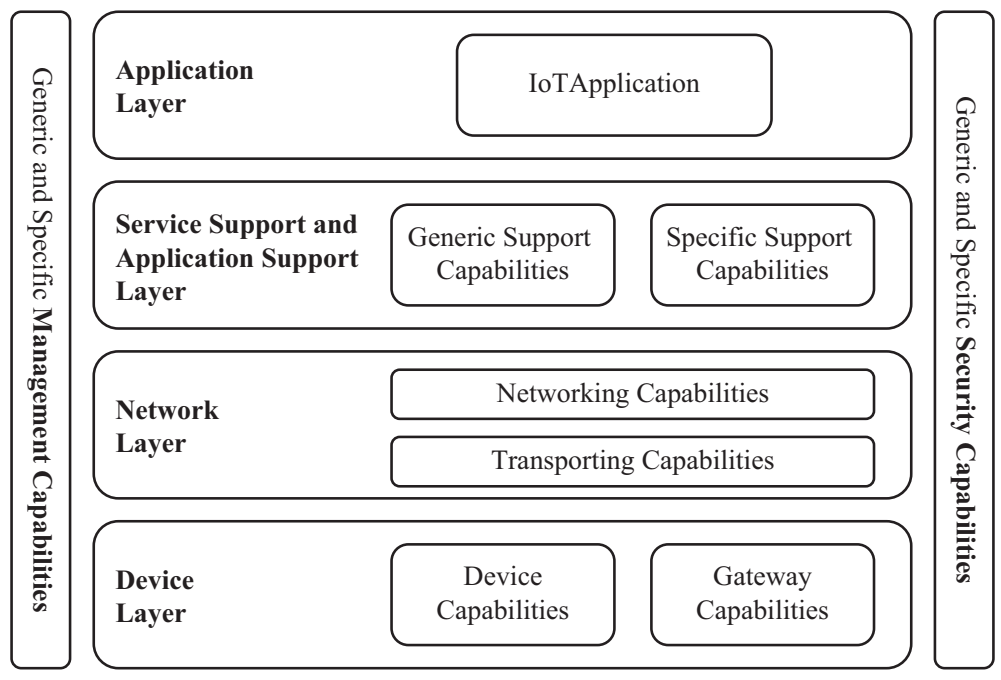

Fig. 8.1 IoT architecture. (Adapted from ITU 2012) 
sector by 2023 (Cisco 2013a, b). Most of the value generated by IoT is linked to increased productivity and efficiency, cost reduction, better customer/citizen experience, faster innovation and new revenue streams (Cisco 2013a, b; Lynn et al. 2018).

Smart factories, for example, leverage data generated by different types of sensors to track the location of materials, machines, and other moveable assets in real time therefore enabling self-organising production lines, seamless synchronisation of production schedules and just-in-time supply chain management (Bansal 2019). The reduced number of people required to manage similar factories, lower inventories, and improved production quality could increase manufacturing efficiency by 27 per cent and add between $\$ 500$ billion and $\$ 1.5$ trillion in value to the global economy by 2022 (Capgemini 2017). Similarly, sensors embedded in a number of small connected devices enable remote monitoring of energy optimisation for smart buildings (King and Perry 2017).

Smart cities also represent a focus area with regard to IoT applications. In the context of smart cities, not only smart buildings, but also smart mobility and connected cars play a critical role (Singh 2016). Sensors can be used to map, for example, available parking slots throughout the city therefore reducing driving times and increasing the quality of life of citizens. Similarly, connected vehicles can provide better integration between different transport services and represent a breakthrough for the adoption of more efficient Mobility-as-a-Service solutions (Lennert et al. 2011; OECD 2019).

\subsection{A Value Mapping Framework for the Internet OF THINGS}

While the technological infrastructure of IoT has attracted most of the attention from industry and academia (Del Giudice 2016), this is only part of the organisational ecosystem that enterprises have to build around their IoT offering. In this section, we discuss three parts of the IoT business value ecosystem - the value creators and generators, investment, and value generation and monetisation. We bring these together by adapting and extending Mikalef et al.'s (2019) value mapping framework for business data analytics. 


\subsubsection{Value Creators and Consumers}

Mapping business value in IoT depends heavily on the perspective taken. The five main categories of actors for whom the IoT can generate value are (1) computing infrastructure providers, for example, hyperscale cloud service providers, (2) network infrastructure providers e.g. telecommunications companies, (3) application developers and providers (e.g. SAP), (4) device manufacturers or providers (e.g. Bosch or Apple), and (5) end users, whether organisations or consumers. Actors can play more than one role and indeed may create value together, for example, through $\mathrm{co}^{-}$ creation. Regardless, to generate and capture the value from IoT, these actors must make investments.

\subsubsection{Investment}

Smart devices range from simple sensors with limited storage and processing power to relatively more advanced and complex devices such as smartphones. These devices are key enablers of big data as they generate constant streams of data that then get processed and analysed in order to return better services/products to the final user (Chen et al. 2012; Chanson et al. 2019). The expectation is that the IoT infrastructure enables these devices to interact with each other and with other systems with minimal latency regardless of their location or local computing power (Lynn et al. 2018). The traditional cloud computing paradigm where all the data is sent to a centralised (remote) cloud infrastructure, processed and sent back to the local device was not designed to meet the requirements of the IoT world.

The new infrastructure paradigm requires a continuum of computing resources activity from the cloud to the "thing" (C2T) where computing resources are located in the cloud, at the thing (edge computing), and/or somewhere in between (fog computing). As such, IoT is effectively driving the transformation of cloud computing in to a decentralised service architecture. Some of these new computing paradigms - fog computing, edge computing and dew computing are defined in Chap. 1. In this new technological landscape, the success or failure of an enterprise IoT service depends on the quality of the service provided by both cloud service providers and network operators, who have to decide where best to locate compute and storage resources along the cloud-to-thing continuum in order to meet Quality of 
Service and Quality of Experience (QoE) requirements. The IoT assumes a multi-layered operational context with long IT value chains, where multiple actors have to work in sync in order to manage system complexity, while delivering an agreed QoE to the final user. In this context, the availability and quality of in-house IT "know-how" and "know-why" is almost as important as the "know-who" (Rennie 1999; Uden and He 2017). While the implications of IT investments on human capital and human resources available within the organisation are relatively simple to foresee, the strategic benefits of relational capital ${ }^{1}$ (the "know who") or the resources required to improve it can be easily overlooked (Zardini et al. 2015).

The scale and complexity of data generated by smart end-points in the IoT is so complex, it is no longer realistic for IT teams to cost-effectively foresee and manage manually the infrastructure underlying the IoT or the data generated by the IoT on a detailed level due to high levels of dynamism and dependencies across the cloud-to-thing continuum (Domaschka et al. 2020). It is therefore necessary for enterprises to invest in organisationwide analytics capability to realise value from the data generated by smart devices (Gupta and George 2016; Wamba et al. 2017) but also to manage the infrastructure and service chain underlying the IoT. As such, data analytics skills and resources are on the must-have list for enterprises that want to leverage IoT. However, given the high demand and scarcity of such resources, it is unsurprising that organisations are increasingly investing in algorithmic intelligence, one such example being AI/Ops-machine learning and artificial intelligence for IT operations (AI/Ops). It has also become evident that organisations must adopt a perspective that goes beyond the technical side when considering the effects and deployment of analytics (Mikalef et al. 2018). Skills and resources availability though is not enough to extract value from IoT. Enterprises have to find their way to combine all skills and resources in order to create unique capabilities which are aligned with the strategic objectives and allow them to adapt to the ever-changing competing landscape (Côrte-Real et al. 2019). Implementing a strategic approach to IoT and data investments and creating routines for faster development and deployment may represent key enablers of faster innovation and higher value creation.

\footnotetext{
${ }^{1}$ Relational capital can be defined as "all relationships-market relationships, power relationships and cooperation-established between firms, institutions and people, which stem from a strong sense of belonging and a highly developed capacity of cooperation typical of culturally similar people and institutions" (Capello and Faggian 2005, p. 75).
} 


\subsubsection{Value Generation and Monetisation}

Irrespective of whether an enterprise adopts IoT for serving internal or external customers, the investment is justified only if the value generated exceeds the investment required. For a comprehensive investment evaluation of IoT though, the concept of value needs to be expanded to include the total value generated for all stakeholders (e.g. investors, employees, customers and suppliers) (Wolf et al. 2019). According to Haller et al. (2009), there are two main sources where enterprises can generate business value from the IoT: real world visibility and business process decomposition. Real word visibility is related to the fact that IoT bridges the gap between the physical and the digital words. In so doing, IoT provides enterprises with real-time insights in to what is happening in the real world thus enabling more effective optimisation, and better decision making. Business process decomposition relates to the fact the distributed nature of the IoT infrastructure enables more decentralised business processes therefore increased scalability, performance, and innovation.

Unfortunately, creating value is not enough. In an enterprise context, value is only relevant when captured and somehow monetised (Osterwalder et al. 2005; Zott et al. 2011), either directly (tangible benefits) or indirectly (intangible benefits). Hui (2014) provides a comparison between the main drivers of value creation and value capture of traditional and IoT products (Table 8.1 ).

Table 8.1 Mindset for the IoT industry. (Adapted from Hui 2014)

\begin{tabular}{|c|c|c|}
\hline Value creation & Traditional product mindset & IoT mindset \\
\hline Customer needs & $\begin{array}{l}\text { Solve for existing needs and } \\
\text { lifestyle in a reactive manner }\end{array}$ & $\begin{array}{l}\text { Address real-time and emergent needs } \\
\text { in a predictive manner }\end{array}$ \\
\hline Offering & $\begin{array}{l}\text { Standalone product that } \\
\text { becomes obsolete over time }\end{array}$ & $\begin{array}{l}\text { Product refreshes through over-the-air } \\
\text { updates and has synergy value }\end{array}$ \\
\hline Role of data & $\begin{array}{l}\text { Single point data is used for } \\
\text { future product requirements }\end{array}$ & $\begin{array}{l}\text { Information convergence creates the } \\
\text { experience for current products and } \\
\text { enables services }\end{array}$ \\
\hline \multicolumn{3}{|l|}{ Value capture } \\
\hline Path to profit & Sell the next product or device & $\begin{array}{l}\text { Enable recurring revenue and increase } \\
\text { efficiency }\end{array}$ \\
\hline Control points & $\begin{array}{l}\text { Potentially includes commodity } \\
\text { advantages, IP ownership, and } \\
\text { brand }\end{array}$ & $\begin{array}{l}\text { Adds personalisation and context; } \\
\text { network effects between products }\end{array}$ \\
\hline $\begin{array}{l}\text { Capability } \\
\text { development }\end{array}$ & $\begin{array}{l}\text { Leverage core competencies, } \\
\text { existing resources and processes }\end{array}$ & $\begin{array}{l}\text { Understand how other ecosystem } \\
\text { partners make money }\end{array}$ \\
\hline
\end{tabular}


With regard to value creation, data and information availability and faster time-to-market clearly play a central role. Valuable IoT solutions combine and integrate "thing"-based functions with IT-based functions (Fleisch et al. 2017) and separate the information flow generated by the device from its physical attributes (Wolf et al. 2019). As such, information (data) generates value in itself as it enables data-driven service innovation, real-time interactions with customers and to better predict future or emerging customer needs (Bohli et al. 2009; Bucherer and Uckelmann 2011; Holler et al. 2015). The IT-based function of IoT products is arguably the one that adds most value and the fact that each device is connected to the network, and to each other, allows providers to implement updates and introduce additional features "over the air". This dramatically reduce the time-to-market of innovation and it is particularly important for physical products with a longer lifecycle than software. A typical example comes from the automotive industry where Tesla Motors introduced the Autopilot function in to tens of thousands of cars already sold overnight through a software update (Kessler and Buck 2017).

IoT solutions also enable the creation of digital platforms where multiple actors can benefit from the unprecedented amount of information generated by connected devices. The value of information is nonexhaustive. On the contrary, it increases with use (Bohli et al. 2009). The amount of information available in the IoT world makes it the perfect environment for the nurturing inter-organisational collaborations and innovation, and for leveraging network effects which would ultimately benefit all stakeholders (Mejtoft 2011). IoT also allows enterprises to shift from unit-based revenue streams to value-based pricing which are more flexible and based on the value of service and information provided to the final user (Kindström 2010). However, this implies that the service provider is able to measure the value parameter associated with specific services and provide customers with transparent and clear value proposition (Kindström 2010).

Finally, IoT investments should ultimately provide the enterprise with the basis for creating a competitive advantage. This is easier said than done; in the IoT world, success lays on the edge between open innovation and collaboration, and internal knowledge management (Santoro et al. 2018). This is even more challenging when the competitive and 
technological landscape is in a constant state of change. Teece et al. (1997, p. 5) suggest that organisations should develop their dynamic capabilities "to integrate, build, and reconfigure internal and external competences to address rapidly changing environments". However, potential configurations are contingent upon the specific environment in which an organisation operates (Pavlou and El Sawy 2010). This implies that managers should develop and evaluate their own strategic approach to IoT as the impacts of technology investments permeate the entire business model and go well beyond the technical components.

\subsubsection{Bring It All Together: A Value Mapping Framework for the Internet of Things}

Figure 8.2 provides a graphical overview of our value mapping framework for the Internet of Things adapted an extended from Mikalef et al. (2019) for IoT. This framework is specifically designed to support managers when assessing the value of complex IoT investments.

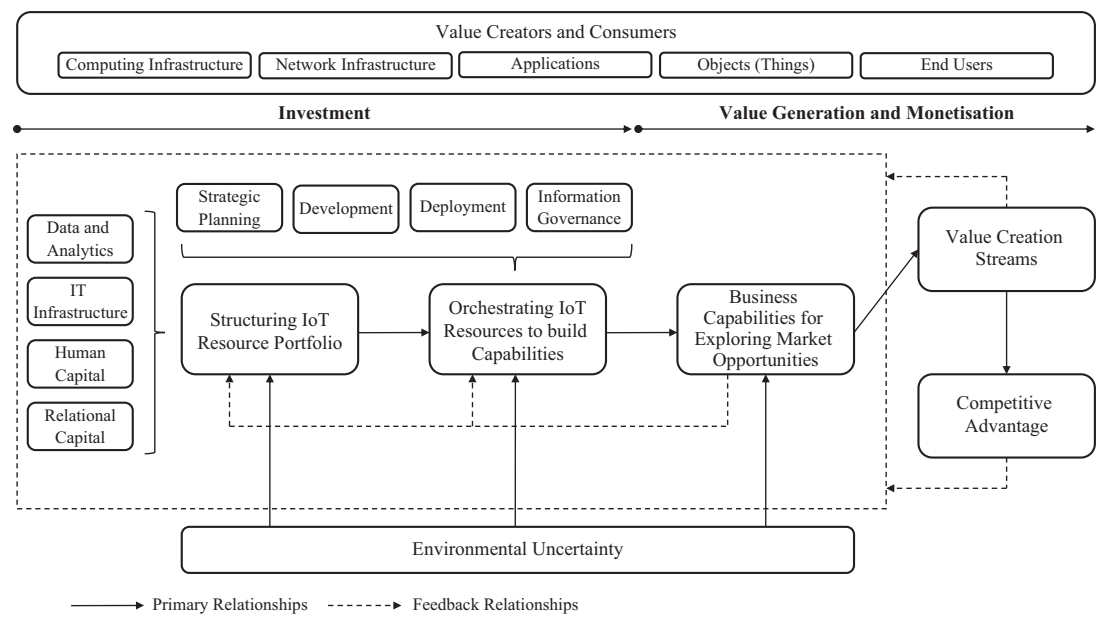

Fig. 8.2 Value mapping framework for the Internet of Things. (Adapted and extended from Mikalef et al. 2019) 


\subsection{Towards a Research Agenda on the Business VALUE OF IOT}

The value mapping framework presented in Fig. 8.2. Table 8.1 can also be used as a point of reference for developing a research agenda on different aspects of the business value of IoT. As IoT is situated at the intersection of a number of technologies, this research agenda may present avenues for future research across a number of disciplines such as information systems, computer science, and management.

IoT is a key enabler of Big Data analytics as sensors allow enterprises to collect constant streams of data of various types to obtain real-time insights into the real world. While data is mostly perceived as a valuable asset. However, storing massive volumes of data may have significant implications from a business and IT perspective; data is only valuable as long as it generates business outcomes (Sivarajah et al. 2017). This last step is not always straightforward and in fact organisations tends to adopt more of a deductive than an inductive approach to analytics projects (Constantiou and Kallinikos 2015). It can be hard sometimes to understand what kind of insights can be extracted from a specific type of data ex-ante. In the context of IoT, sensors need be embedded in to physical products/devices and the temptation to include different kind of sensors can be high as it may be the difficult to add them post-sale/installation. These sensors may generate streams of data that may remain unused and have regulatory and cost implications. In contrast, if a sensor that is able to capture valuable data is missing from the device, this may generate significant loss in revenues and/or costs post-sale for updates or replacements. Future research may clarify what are the benefits and challenges associated with inductive or deductive approaches toward analytics and potentially develop guidelines for IoT data monetisation.

From an infrastructure perspective, IoT introduces significant complexity mostly due to the fact that it requires a number of actors (e.g., cloud providers, cloud carriers, cloud brokers, edge device producers, etc.) to work together towards the same goal, that is, a seamless user experience. Some of the technological investments made by one actor may impact positively or negatively the others involved in the IoT value chain and therefore generate unexpected outcomes. A comprehensive evaluation of potential investments and dependencies in the wider IoT infrastructure needs to be carefully evaluated in the context of a longer service chain, and consequently wider value chain, rather than at an organisational level. 
Future research may investigate expected or unexpected value transfer with the IoT supply chain as a consequence of IT investments therefore providing useful insights with regard to supply chain value creation.

Human and relational capital represent the "softer" side of the IoT resource portfolio. Sousa and Rocha (2019) identify three main groups of skills that organisations need to have in order to create digital businesses, that is, innovation skills, leadership skills and management skills. While the need for further skills development in IT-oriented contexts is widely recognised, there is still a need for clear guidelines on how to develop such skills and how to update them over time in order to meet the ever-changing market requirements (Sousa and Rocha 2019). Relational capital consists of relations that the company creates with different stakeholders. This is particularly important in the context of IoT which is mostly characterised by high competition, a complex value chain and low switching costs. Future research may investigate how relational capital is built in this context and hot it translates in business outcomes.

Resource orchestration is a key element for extracting value for IoT solutions. Collecting appropriate resources is not enough to be successful in the IoT world. Enterprises need to develop organisation-wide capabilities for leveraging IoT resources (Gupta and George 2016; Mikalef et al. 2019 ) but how this can be achieved is still unclear. Future research may provide organisations with a framework for developing such capabilities over time and map out potential enablers and constraining forces.

Once value it has been created, enterprises should be able to capture and somehow measure it. Value capturing can be mostly related to suitable business models for IoT. While previous studies have looked at the highlevel impact of IoT on business models (Hui 2014; Dijkman et al. 2015; Fleisch et al. 2015; Metallo et al. 2018), future research may delve into each of the key elements of business models and explore different options available to enterprises to monetise their IoT solutions. Finally, enterprises should be able to measure the value generated by IoT investments. Enterprises are profit-driven organisations where value is typically measured in monetary terms. Over time, a number of methodologies to estimate the financial value generated by IT investments have been developed (see Table 8.2).

The length, complexity and opacity of the chain of service provision in the IoT may make the quantitative measurement of IoT business value extremely difficult, not least establishing causal relationships. Measuring the business value of technology investments can be considered both a 
Table 8.2 Selected financial metrics for measuring the business value of IT investments

\begin{tabular}{|c|c|}
\hline Metric & Description \\
\hline $\begin{array}{l}\text { Cost-benefit } \\
\text { analysis } \\
\text { (CBA) }\end{array}$ & $\begin{array}{l}\text { CBA compares costs to benefits and therefore represents a measure of } \\
\text { efficiency. }\end{array}$ \\
\hline $\begin{array}{l}\text { Economic } \\
\text { value added } \\
\text { (EVA) }\end{array}$ & $\begin{array}{l}\text { EVA measures the value generated by an investment net of all costs } \\
\text { including the cost of the capital invested. When evaluating different } \\
\text { investment opportunities with similar expected returns, managers should } \\
\text { opt for the one that generates the highest EVA. }\end{array}$ \\
\hline $\begin{array}{l}\text { Internal rate } \\
\text { of return } \\
\text { (IRR) }\end{array}$ & $\begin{array}{l}\text { IRR represents the discount rate that would return a value of zero for } \\
\text { NPV. Financially valuable investments have an IRR that is equal or higher } \\
\text { than the desired or minimum rate of return. }\end{array}$ \\
\hline $\begin{array}{l}\text { Net present } \\
\text { value (NPV) }\end{array}$ & $\begin{array}{l}\text { NPV is a measure of the present value of the future cash flows generated } \\
\text { by an investment, net of the initial capital outlay and discounted by a rate } \\
\text { that reflects the time value of money and the risk of the investment. }\end{array}$ \\
\hline $\begin{array}{l}\text { Payback } \\
\text { period }\end{array}$ & $\begin{array}{l}\text { Payback period measures the time needed for a project to repay the initial } \\
\text { investment. Investments with a shorter payback period may be more } \\
\text { attractive however this metric does not provide any indication about the } \\
\text { value generated after the payback period and therefore investment } \\
\text { decisions should not be based on this metric alone. }\end{array}$ \\
\hline $\begin{array}{l}\text { Return on } \\
\text { investment } \\
\text { (ROI) }\end{array}$ & $\begin{array}{l}\text { ROI is an accounting ratio that compares the net benefit generated by an } \\
\text { investment to the overall investment required. As such, it allows to } \\
\text { directly compare investments of different scale. }\end{array}$ \\
\hline $\begin{array}{l}\text { Total cost of } \\
\text { ownership } \\
\text { (TCO) }\end{array}$ & $\begin{array}{l}\text { This metric captures the overall cost of single components of an IT } \\
\text { system such as hardware, software, maintenance etc. TCO is relatively } \\
\text { simple to calculate but it does not capture the benefits the system } \\
\text { generates to the organisation and therefore it only provides an } \\
\text { incomplete picture of the overall investment. }\end{array}$ \\
\hline
\end{tabular}

science and an art (Tallon et al. 2020). In fact, the use of technology in enterprises today is so widespread and pervasive that the impacts of IT investments typically go beyond tangible operational benefits and costs to include organisational and business impacts (e.g., increased agility, faster innovation, better employees or customer experience) that are intangible in nature and therefore hard to quantify (Tallon and Kraemer 2007; Tallon et al. 2020; Rosati and Lynn 2020). This is unlikely to change for IoT and, indeed, may be exacerbated. The increasing adoption of IT "as-aService" makes it easier to forecast, monitor and quantify operational costs (Rosati et al. 2017). This leaves managers with more time to evaluate potential intangible impacts of the investment. Unfortunately, there is no 
one-size-fits-all methodology for doing this. Tallon (2014) proposes a distributed sensemaking model where managers, in the absence of objective data, rely on the views of multiple internal stakeholders to notice, weigh, and filter informational cues from various sources in order to reach a reasoned, balanced judgment of the intangible value delivered by the IT investment. Future research may map out tangible and intangible costs and benefits generated by different types of IT investments for different actors along the IoT value chain, and provide guidelines to measuring the business value of IoT.

\subsection{Conclusion}

In this chapter, we presented a business value mapping framework for the Internet of Things with purpose of identifying the main actors, cost and value drivers associated with IoT. The scale, interconnectivity and complexity of the Internet of Things makes conceptualising and measuring business value extremely challenging. Despite this, given the opportunity and risks, it is essential. Building on Mikalef et al. (2019), we provide a preliminary framework for mapping business value in the IoT that can be used by enterprises to identify areas for strategic investment and consideration in this exciting new space.

\section{REFERENCES}

Agrawal, D., S. Das, and A. El Abbadi. 2011. Big Data and Cloud Computing: Current State and Future Opportunities. Proceedings of the 14th International Conference on Extending Database Technology, 530-533. ACM.

Bansal, N. 2019. This is How a Smart Factory Actually Works. World Economic Forum. https://www.weforum.org/agenda/2019/06/connectivity-is-drivinga-revolution-in-manufacturing/.

Bohli, J.M., C. Sorge, and D. Westhoff. 2009. Initial Observations on Economics, Pricing, and Penetration of the Internet of Things Market. ACM SIGCOMM Computer Communication Review 39 (2): 50-55.

Bucherer, E., and D. Uckelmann. 2011. Business Models for the Internet of Things. In Architecting the Internet of Things, 253-277. Berlin, Heidelberg: Springer.

Capello, R., and A. Faggian. 2005. Collective Learning and Relational Capital in Local Innovation Processes. Regional Studies 39 (1): 75-87. 
Capgemini. 2017. Smart Factories: How can Manufacturers Realize the Potential of Digital Industrial Revolution. https://www.capgemini.com/wp-content/ uploads /2017/05/dti-smart-factories-full-report-rebranded-web-version_16032018.pdf.

Chanson, M., A. Bogner, D. Bilgeri, E. Fleisch, and F. Wortmann. 2019. Blockchain for the IoT: Privacy-Preserving Protection of Sensor Data. Journal of the Association for Information Systems 20 (9): 10.

Chen, H., R.H. Chiang, and V.C. Storey. 2012. Business Intelligence and Analytics: From Big Data to Big Impact. MIS Quarterly 36 (4): 1165-1188.

Cisco. 2013a. Embracing the Internet of Everything to Capture Your Share of \$14.4 Trillion. https://www.cisco.com/c/dam/en_us/about/ac79/docs/ innov/IoE_Economy.pdf.

- 2013b. Internet of Everything: A \$4.6 Trillion Public-Sector Opportunity. https://www.cisco.com/c/dam/en_us/about/business-insights/docs/ioepublic-sector-vas-white-paper.pdf.

Constantiou, I.D., and J. Kallinikos. 2015. New Games, New Rules: Big Data and the Changing Context of Strategy. Journal of Information Technology 30 (1): 44-57.

Côrte-Real, N., P. Ruivo, and T. Oliveira. 2019. Leveraging Internet of Things and Big Data Analytics Initiatives in European and American Firms: Is Data Quality a Way to Extract Business Value? Information \& Management 57: 103141 .

Del Giudice, M. (Ed.). (2016). Discovering the Internet of Things (IoT): technology and business process management, inside and outside the innovative firms. Emerald.

Dijkman, R.M., B. Sprenkels, T. Peeters, and A. Janssen. 2015. Business Models for the Internet of Things. International Journal of Information Management 35 (6): 672-678.

Domaschka, Jorg, Frank Griesinger, Mark Leznik, Per-Olov Östberg, Keith Ellis, Paolo Casari, Frank Fowley, and Theo Lynn. 2020. Towards an Architecture for Reliable Capacity Provisioning for Distributed Clouds. In Managing Distributed Cloud Applications and Infrastructure: A Self-Optimising Approach. Cham: Springer.

Fleisch, E., M. Weinberger, and F. Wortmann. 2015. Business Models and the Internet of Things. In Interoperability and Open-Source Solutions for the Internet of Things, 6-10. Cham: Springer.

- 2017. Geschäftsmodelle im Internet der Dinge. In Industrie 4.0, 1-16. Wiesbaden: Springer Vieweg.

Gupta, M., and J.F. George. 2016. Toward the Development of a Big Data Analytics Capability. Information \& Management 53 (8): 1049-1064. 
Haller, S., A. Karnouskos, and C. Schroth. 2009. The Internet of Things in an Enterprise Context. In Future Internet Symposium, 14-28. Berlin, Heidelberg: Springer.

Holler, J., V. Tsiatsis, C. Mulligan, S. Avesand, S. Karnouskos, and D. Boyle. 2015. From Machine-to-Machine to the Internet of Things. Elsevier.

Hui, G. 2014. How the Internet of Things Changes Business Models. Harvard Business Review 92 (7/8): 1-5.

IDC. 2018. ICT Spending Forecast-2018-2022 Forecast. https://www.idc. $\mathrm{com} /$ promo/global-ict-spending/forecast.

- 2019. IDC Forecasts Worldwide Spending on the Internet of Things to Reach $\$ 745$ Billion in 2019, Led by the Manufacturing, Consumer, Transportation, and Utilities Sectors. https://www.idc.com/getdoc.jsp?contai nerId=prUS44596319.

ITU. 2012. Overview of the Internet of Things. http://handle.itu. int $/ 11.1002 / 1000 / 11559$.

Ji, C., Y. Li, W. Qiu, U. Awada, and K. Li. 2012. Big Data Processing in Cloud Computing Environments. 2012 12th International Symposium on Pervasive Systems, Algorithms and Networks, 17-23. IEEE.

Karkouch, A., H. Mousannif, H. Al Moatassime, and T. Noel. 2016. Data Quality in Internet of Things: A State-of-the-Art Survey. Journal of Network and Computer Applications 73: 57-81.

Kessler, T., and C. Buck. 2017. How Digitization Affects Mobility and the Business Models of Automotive OEMs. In Phantom Ex Machina, 107-118. Cham: Springer.

Kindström, D. 2010. Towards a Service-based Business Model-Key Aspects for Future Competitive Advantage. European Management Journal 28 (6): 479-490.

King, J., and C. Perry. 2017. Smart Buildings: Using Smart Technology to Save Energy in Existing Buildings. https://aceee.org/sites/default/files/publications/researchreports/al701.pdf.

Lennert, F., C. Macharis, V. van Acker, and L. Neckermann. 2011. Smart Mobility and Services-Expert Group Report. https://ec.europa.eu/transparency/regexpert/index.cfm?do=groupDetail.groupDetailDoc\&id=34596\&no=1 .

Lynn, T., P. Rosati, and P.T. Endo. 2018. Toward the Intelligent Internet of Everything: Observations on Multidisciplinary Challenges in Intelligent Systems Research. Coloquio Doctorados: Tecnología, Ciencia y Cultura: una visión globa. Puebla, Mexico..

Mejtoft, T. 2011. Internet of Things and Co-creation of Value. 2011 International Conference on Internet of Things and 4th International Conference on Cyber, Physical and Social Computing, 672-677. IEEE.

Metallo, C., R. Agrifoglio, F. Schiavone, and J. Mueller. 2018. Understanding Business Model in the Internet of Things Industry. Technological Forecasting and Social Change 136: 298-306. 
Mikalef, P., I.O. Pappas, J. Krogstie, and M. Giannakos. 2018. Big Data Analytics Capabilities: A Systematic Literature Review and Research Agenda. Information Systems and e-Business Management 16 (3): 547-578.

Mikalef, P., I.O. Pappas, J. Krogstie, and P.A. Pavlou. 2019. Big Data and Business Analytics: A Research Agenda for Realizing Business Value. Information \& Management.

Miorandi, D., Sicari, S., De Pellegrini, F., \& Chlamtac, I. (2012). Internet of things: Vision, applications and research challenges. Ad hoc networks, 10(7), 1497-1516.

OECD. 2019. Enhancing the Contribution of Digitalisation to Smart Cities of the Future. https://www.oecd.org/cfe/regional-policy/Smart-Cities-FINAL.pdf.

Osterwalder, A., Y. Pigneur, and C.L. Tucci. 2005. Clarifying Business Models: Origins, Present, and Future of the Concept. Communications of the Association for Information Systems 16 (1): 1.

Pavlou, P.A., and O.A. El Sawy. 2010. The "Third Hand": IT-Enabled Competitive Advantage in Turbulence Through Improvisational Capabilities. Information Systems Research 21 (3): 443-471.

Rennie, M. 1999. Accounting for Knowledge Assets: Do We Need a New Financial Statement? International Journal of Technology Management 18 (5-8): 648-659.

Rosati, P., and T. Lynn. 2020. Measuring the Business Value of Infrastructure Migration to the Cloud. In Measuring the Business Value of Cloud Computing, ed. T. Lynn, J.G. Mooney, P. Rosati, and G. Fox. Springer.

Rosati, P., G. Fox, D. Kenny, and T. Lynn. 2017. Quantifying the Financial Value of Cloud Investments: A Systematic Literature Review. 2017 IEEE International Conference on Cloud Computing Technology and Science (CloudCom), 194-201. IEEE.

Sagiroglu, S., and D. Sinanc. 2013. Big Data: A Review. 2013 International Conference on Collaboration Technologies and Systems (CTS), 42-47. IEEE.

Santoro, G., D. Vrontis, A. Thrassou, and L. Dezi. 2018. The Internet of Things: Building a Knowledge Management System for Open Innovation and Knowledge Management Capacity. Technological Forecasting and Social Change 136: 347-354.

Singh, K. 2016. Contribution on Smart Urban Mobility for Safe, Inclusive, Resilient and Sustainable Cities. https://www.iru.org/sites/default/ files/2016-10/0354_UN_Habitat_report_web-FINAL.pdf.

Sivarajah, U., M.M. Kamal, Z. Irani, and V. Weerakkody. 2017. Critical Analysis of Big Data Challenges and Analytical Methods. Journal of Business Research 70: 263-286.

Sousa, M.J., and Á. Rocha. 2019. Skills for Disruptive Digital Business. Journal of Business Research 94: 257-263.

Tallon, P.P. 2014. Do You See What I See? The Search for Consensus Among Executives' Perceptions of IT Business Value. European Journal of Information Systems 23 (3): 306-325. 
Tallon, P.P., and K.L. Kraemer. 2007. Fact or Fiction? A Sensemaking Perspective on the Reality Behind Executives' Perceptions of IT Business Value. Journal of Management Information Systems 24 (1): 13-54.

Tallon, P.P., J.G. Mooney, and M. Duddek. 2020. Measuring the Business Value of IT. In Measuring the Business Value of Cloud Computing. Springer.

Teece, D.J., G. Pisano, and A. Shuen. 1997. Dynamic Capabilities and Strategic Management. Strategic Management Journal 18 (7): 509-533.

Uden, L., and W. He. 2017. How the Internet of Things can Help Knowledge Management: A Case Study from the Automotive Domain. Journal of Knowledge Management 21 (1): 57-70.

Wamba, S.F., A. Gunasekaran, S. Akter, S.J.F. Ren, R. Dubey, and S.J. Childe. 2017. Big Data Analytics and Firm Performance: Effects of Dynamic Capabilities. Journal of Business Research 70: 356-365.

Wolf, V., J. Stumpf-Wollersheim, and L. Schott. 2019. The Internet of Things in a Business Context: Implications with Respect to Value Creation, Value Drivers, and Value Capturing. In Digital Entrepreneurship, 185-197. Cham: Springer.

Zardini, A., F. Ricciardi, and C. Rossignoli. 2015. The Relational Capital of the IT Department: Measuring a Key Resource for Creating Strategic Value. Journal of Intellectual Capital 16 (4): 835-859.

Zott, C., R. Amit, and L. Massa. 2011. The Business Model: Recent Developments and Future Research. Journal of Management 37 (4): 1019-1042.

Open Access This chapter is licensed under the terms of the Creative Commons Attribution 4.0 International License (http://creativecommons.org/licenses/ by $/ 4.0 /$ ), which permits use, sharing, adaptation, distribution and reproduction in any medium or format, as long as you give appropriate credit to the original author(s) and the source, provide a link to the Creative Commons licence and indicate if changes were made.

The images or other third party material in this chapter are included in the chapter's Creative Commons licence, unless indicated otherwise in a credit line to the material. If material is not included in the chapter's Creative Commons licence and your intended use is not permitted by statutory regulation or exceeds the permitted use, you will need to obtain permission directly from the copyright holder.

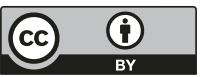

